\title{
Radiotherapy for Muscle-invasive Bladder Cancer in Very Elderly Patients
}

\author{
TOSHIYA MAEBAYASHI ${ }^{1}$, NAOYA ISHIBASHI ${ }^{1}$, TAKUYA AIZAWA ${ }^{1}$, MASAKUNI SAKAGUCHI $^{1}$, \\ KATSUHIKO SATO ${ }^{2}$, TSUYOSHI MATSUI ${ }^{2}$, KENYA YAMAGUCHI $^{2}$ and SATORU TAKAHASHI ${ }^{2}$ \\ Departments of ${ }^{1}$ Radiology, and ${ }^{2}$ Urology, Nihon University School of Medicine, Tokyo, Japan
}

\begin{abstract}
Aim: The standard therapy for muscle invasive bladder cancer $(M I B C)$ is radical total cystectomy; however, radiotherapy $(R T)$ is performed in patients who cannot tolerate surgery due to advanced age. This study aimed to retrospectively examine whether the feasibility of concurrent use of intra-arterial chemotherapy (IAC) can be assessed using both treatment results of RT for MIBC in elderly patients and the G8 Screening Tool. Patients and Methods: We studied 16 patients who had received intra-arterial chemoradiotherapy (IACRT) or RT alone between February 2004 and December 2012. The median age was 83 (range=75-91) years. Twelve patients had stage II and 4 had stage III disease. Ten patients received IACRT and six received $R T$ alone. In order to determine whether the G8 score distinguishes patients for treatment with IACRT or RT alone, we calculated the cut-off of the G8 score for addition of IAC. Results: The overall median G8 score was 12 (range=9-15), with scores of 13 (range=12-15) in the IACRT group and 10 (range=9-11) in the $R T$-alone group. The G8 score was 12 or more in all patients in the IACRT group. The median follow-up period was 35 (range=6-64) months. The 2- and 5-year overall survival rates were $80 \%$ and $66.7 \%$ in the IACRT group. The 1- and 2-year survival rates in the RT-alone group were $50 \%$ and $25 \%$, respectively. Regarding late adverse events, only one patient experienced grade 2 genitourinary toxicity. Conclusion: IACRT was considered to be useful for the treatment of MIBC in elderly patients, with tolerable adverse events. Moreover, used in conjunction with age and performance status, the G8 Screening Tool is potentially applicable for determining the
\end{abstract}

Correspondence to: Toshiya Maebayashi, MD, Ph.D., Department of Radiology, Nihon University School of Medicine, 30-1 Oyaguchi Kami-cho, Itabashi-ku, Tokyo, 173-8610, Japan. Tel: +81 339728111 (ext. 8328), Fax: +81 339582454, e-mail: maebayashi.toshiya@nihon-u.ac.jp

Key Words: Bladder cancer, radiation therapy, intra-arterial chemotherapy, elderly patients, G8 Screening Tool. feasibility of performing IAC. To our knowledge, this is the first report about the correlation between $G 8$ score and feasibility of IAC.

The standard therapy for muscle-invasive bladder cancer (MIBC) is radical total cystectomy. However, the number of cases experiencing recurrence is not insignificant (1-3). Since the peak age range for urinary bladder cancer incidence is 60 to 70 years of age (4), it is necessary to assume a higher incidence of perioperative complications in these patients than in young patients.

To date, no studies have compared surgery and chemoradiotherapy (CRT). Moreover, the results of a phase III clinical study comparing radiotherapy (RT) alone with CRT showed no improvement in the percentage of surviving patients with the add-on effect of chemotherapy $(5,6)$. At present, RT alone, or CRT with cisplatin etc., with the expectation of a radiosensitizing action, is performed in patients who cannot undergo surgery due to advanced age or comorbidities. We consider the efficacy of RT on MIBC to be relatively high, with tolerable adverse events. When intraarterial chemotherapy (IAC) is concurrently used at our hospital, various measures are taken to reduce adverse events.

RT indications for MIBC, methods, and total radiation doses vary (7), and there is no consensus on the types of anticancer drugs that should be used, nor on the optimal mode of CRT administration. However, combined IAC and RT (IACRT) is more commonly used in Japan than in other countries (8-10).

In Japan, people 65 to 75 years of age are classified as the early-stage elderly and those 75 years and older as the latterstage elderly (the late elderly) (11). As treatment policy cannot be determined based on age alone, we sought to examine whether the use of chemotherapy could be determined with the G8 Screening Tool (12). The G8 Screening Tool is now increasingly used to evaluate the prognosis for functional decline in elderly patients and the overall survival rate (31), because it is easier to use than other screening tools such as the Vulnerable Elders Survey 
(VES-13) (30), the Flemish version of the Triage Risk Screening Tool (f TRST), and the abbreviated comprehensive geriatric assessment (CGA) (31). We retrospectively examined whether IACRT was the optimal treatment choice, using treatment results of RT for MIBC in elderly patients and the G8 Screening Tool (12).

\section{Patients and Methods}

Ethics approval and consent to participate. All clinical procedures were performed in accordance with the ethical standards of the institutional and national research committee and with the 1964 Helsinki declaration and its later amendments or comparable ethical standards.

Patient characteristics. We retrospectively studied 16 patients who had received RT alone or IACRT between 2004 and 2012. In all patients, transurethral resection of bladder tumor (TURBT) was the procedure performed for urinary bladder cancer, and pathological tissues were diagnosed as urothelial carcinoma or MIBC. Six patients received RT alone and 10 received IACRT. The baseline characteristics of our patients are presented in Table I. There were 11 men and five women, ranging in age from 75 to 91 years (median $=83$ years). Twelve patients had clinical stage II and 4 had stage III disease. Six patients received RT alone and 10 received IACRT. Cisplatin was a key drug in chemotherapy. The Eastern Cooperative Oncology Group (ECOG) Performance Status (PS) was 1 in all patients. Bladder preservation or local control was defined as the state in which there was no recurrent or persistent tumor in the bladder.

Radiotherapy. The device employed for radiotherapy was the SIEMENS PRIMUS KD2 (SIEMENS Oncology Care Systems, Concord, CA, USA) and Synergy linear accelerator (Elekta Inc., Stockholm, Sweden). For treatment planning, $\mathrm{XiO}$ (version 4.4.04.6.0; Elekta, CA, Germany) and MONACO 5.0 (Elekta Inc., Stockholm, Sweden) was employed and the isocenter dose was calculated by Clarkson's method and Collapsed Cone's method. Irradiation fields were determined as follows: Firstly, a $1.5-\mathrm{cm}$ margin was added to the clinical target volume (CTV=whole bladder), which was the planning target volume (PTV), and then a 5-mm margin was added to the PTV, which was the irradiation field. Irradiation was performed using 10-MV X-rays; irradiation with 4field or more irradiation was performed.

The fractional and total RT doses were, in principle, $1.8 \mathrm{~Gy}$ and 45 Gy, respectively, in patients receiving IACRT and 2 Gy and 50$60 \mathrm{~Gy}$, respectively, in patients receiving RT alone. When the total dose exceeded $50 \mathrm{~Gy}$, additional irradiation was locally administered to lesion sites as boost radiation. In the two patients given $60 \mathrm{~Gy}$ in total, localized irradiation of tumor sites was performed as boost radiation after the dose had exceeded 50 Gy. The irradiation field was the entire urinary bladder alone.

Chemotherapy. In the IACRT group, the drugs were administered via an indwelling catheter in the internal iliac artery over $30 \mathrm{~min}$. Chemotherapy regimens were cisplatin plus tetrahydropyran in six patients $(6 / 10)$, cisplatin plus adriamycin in three patients $(3 / 10)$, and cisplatin plus adriamycin with methotrexate in one patient $(1 / 10)$. The doses given are presented in Table II.
Table I. Patient characteristics. Follow-up periods, sex, age, stage, grade, G8 Screening Tool score and radiation dose are shown, with percentages indicated in parentheses. Other data are presented as the number of patients, with percentages in parentheses.

\begin{tabular}{lccc}
\hline & $\begin{array}{c}\text { RT alone } \\
(\mathrm{n}=6)\end{array}$ & $\begin{array}{c}\text { IACRT } \\
(\mathrm{n}=10)\end{array}$ & $\begin{array}{c}\text { Total } \\
(\mathrm{n}=16)\end{array}$ \\
\hline $\begin{array}{l}\text { Follow-up (months) } \\
\quad \text { Median }\end{array}$ & 12 & 40 & 35 \\
$\quad$ Range & $6-44$ & $7-64$ & $6-64$ \\
Age (years) & & & \\
$\quad$ Median & 87 & 82 & 83 \\
$\quad$ Range & $84-91$ & $75-87$ & $75-91$ \\
Gender & & & \\
$\quad$ Male & $4(67)$ & $8(80)$ & $12(75)$ \\
$\quad$ Female & $2(23)$ & $2(20)$ & $4(25)$ \\
Stage & & & \\
$\quad$ II & $5(83)$ & $7(70)$ & $12(75)$ \\
$\quad$ III & $1(17)$ & $3(30)$ & $4(25)$ \\
Grade & & & \\
$\quad 2$ & $4(67)$ & $2(20)$ & $6(38)$ \\
$\quad 3$ & $2(23)$ & $8(80)$ & $10(62)$ \\
G8 Screening Tool score & & & \\
$\quad$ Median & 10 & 12 & 12 \\
$\quad$ Range & $9-11$ & $12-15$ & $9-15$ \\
Radiation dose (Gy) & & & \\
$\quad$ Median & 50 & 50 & 50 \\
Range & $45-60$ & $45-60$ & $45-60$ \\
\hline
\end{tabular}

RT, Radiotherapy; IACRT, intra-arterial chemoradiotherapy.

G8 Screening Tool. The G8 Screening Tool is a questionnaire for geriatric assessment which contains eight items - nutritional status, weight, mobility, neuropsychological problems, body mass index (BMI), medications and health status (31).

Study objectives. The primary end-points of this study were to determine the cut-off of the G8 score for addition of IAC, overall survival and urinary bladder preservation rates. In order to determine whether the G8 score distinguishes very elderly patients for treatment with IACRT or RT alone, we calculated the cut-off of the G8 score for addition of IAC.

Statistical analysis. Survival was calculated by the Kaplan-Meier method, and differences were expressed at a 5\% significance level with a two-tailed log-rank test. Overall survival was defined as the time between the start of radiotherapy and death or last follow-up for surviving patients. All calculations and survival displays were conducted using the SPSS 21.0J statistical software package (IBM Corp., Armonk, NY, USA). Late complications were graded according to the National Cancer Institute-Common Terminology Criteria (NCI-CTC), Version 4.0 (13).

\section{Results}

G8 score. Overall, the median G8 score was 12 (range=9-15); it was 10 (range=9-11) for the RT-alone group and 13 (range=12-15) for the IACRT group. The G8 score was 12 or more in all patients in the IACRT group (Tables III and IV). 
Table II. Chemotherapy regimens and acute adverse events experienced under therapy.

\begin{tabular}{lccccc}
\hline Regimen & $\mathrm{n}=10$ & $\begin{array}{c}\text { CDDP } \\
(\mathrm{mg})\end{array}$ & $\begin{array}{c}\text { THP-ADM/ADM } \\
(\mathrm{mg})\end{array}$ & $\begin{array}{c}\text { Adverse events } \\
\text { (neutropenia), } \mathrm{n}\end{array}$ & $\begin{array}{c}\text { Acute adverse events } \\
\text { (radiotherapy), } \mathrm{n}\end{array}$ \\
\hline CDDP+THP-ADM & 6 & $60-120$ (median=110) & $18-50$ (median=48) & G1: 1 & Cystitis G1: 1 \\
& & & & G2: 2 & Enterocolitis G1: 1 \\
& & & & G4: 1 & \\
CDDP+ADM & 3 & $75-110$ (median=110) & $30-50$ (median=30) & G2: 2 & Cystitis G1: 2 \\
CDDP+ADM+MTX & 1 & 40 & 25 (plus MTX 25 mg) & None & Cystitis and enterocolitis G1: 1 \\
\hline
\end{tabular}

CDDP, Cisplatin; THP-ADM, pirarubicin; ADM, adriamycin; MTX, methotrexate; G: grade.

Table III. Characteristics of the 10 patients who received intra-arterial chemoradiotherapy.

\begin{tabular}{|c|c|c|c|c|c|c|c|c|c|c|c|}
\hline No. & $\begin{array}{c}\text { Age } \\
\text { (years)/ } \\
\text { gender }\end{array}$ & Stage & $\begin{array}{c}\text { Fractional } \\
\text { dose } \\
\text { (Gy) }\end{array}$ & $\begin{array}{c}\text { Total RT } \\
\text { dose } \\
\text { (Gy) }\end{array}$ & Pathology* & Chemotherapy & $\begin{array}{l}\text { G8 } \\
\text { score }\end{array}$ & $\begin{array}{c}\text { Adverse } \\
\text { event }\end{array}$ & $\begin{array}{l}\text { Hematotoxicity, } \\
\text { neutropenia }\end{array}$ & $\begin{array}{c}\text { Survival } \\
\text { (months), } \\
\text { outcome }\end{array}$ & $\begin{array}{c}\text { Bladder } \\
\text { preservation } \\
\text { (months) }\end{array}$ \\
\hline 1 & $83 / \mathrm{M}$ & II & 2 & 60 & G3 & CDDP+THP-ADM & 12 & Cystitis: G1 & G2 & $\begin{array}{c}\text { 7, Died } \\
\text { from disease }\end{array}$ & 7 \\
\hline 2 & $82 / \mathrm{M}$ & III & 2 & 60 & $\mathrm{G} 2>3$ & $\mathrm{CDDP}+\mathrm{ADM}$ & 15 & Cystitis: G1 & G2 & $\begin{array}{c}\text { 38, Died } \\
\text { from disease }\end{array}$ & 18 \\
\hline 3 & $75 / \mathrm{F}$ & II & 2 & 50 & $\begin{array}{c}\text { G3 with } \\
\text { squamous } \\
\text { differentiation }\end{array}$ & CDDP+THP-ADM & 14 & Enterocolitis: G1 & $\begin{array}{l}\text { Neutropenia: G3 } \\
\text { Thrombopenia: G2 }\end{array}$ & 53 & 53 \\
\hline 4 & $82 / \mathrm{F}$ & II & 1.8 & 45 & $\mathrm{G} 3$ & CDDP+THP-ADM & 12 & Enterocolitis: G1 & G3 & 42 & 27 \\
\hline 5 & $83 / \mathrm{M}$ & II & 1.8 & 45 & $\begin{array}{c}\text { G3 with } \\
\text { squamous } \\
\text { differentiation }\end{array}$ & CDDP+THP-ADM & 13 & None & G3 & 33 & 33 \\
\hline 6 & $87 / \mathrm{M}$ & II & 2 & 50 & $\mathrm{G} 3$ & $\mathrm{CDDP}+\mathrm{ADM}$ & 12 & None & G1 & $\begin{array}{c}\text { 23, Died } \\
\text { from disease }\end{array}$ & 8 \\
\hline 7 & $85 / \mathrm{M}$ & II & 1.8 & 45 & G3 $>2$ & CDDP+ADM & 12 & Enterocolitis: G2 & G2 & 64 & 64 \\
\hline 8 & $78 / \mathrm{M}$ & III & 2 & 56 & $\mathrm{G} 3>2$ & $\mathrm{CDDP}+\mathrm{ADM}$ & 14 & Cystitis: G1 & G3 & 60 & 34 \\
\hline 9 & $77 / \mathrm{F}$ & II & 2 & 60 & G3 & $\mathrm{CDDP}+\mathrm{ADM}+\mathrm{MTX}$ & X 14 & Cystitis: G1 & G0 & $\begin{array}{c}55, \\
\text { Dropped out }\end{array}$ & 55 \\
\hline 10 & 79/M & II & 1.8 & 45 & $\mathrm{G} 2>3$ & CDDP+THP-ADM & 13 & Cystitis: G1 & G4 & 37 & 37 \\
\hline
\end{tabular}

*Urothelial cancer. CDDP, Cisplatin; THP-ADM, pirarubicin; ADM, adriamycin; MTX, methotrexate; G: grade.

Table IV. Characteristics of the six patients who received radiotherapy alone.

\begin{tabular}{|c|c|c|c|c|c|c|c|c|c|c|}
\hline No & $\begin{array}{l}\text { Age (years)/ } \\
\text { gender }\end{array}$ & Stage & $\begin{array}{l}\text { Fractional } \\
\text { dose (Gy) }\end{array}$ & $\begin{array}{c}\text { Total radiation } \\
\text { dose (Gy) }\end{array}$ & Pathology* & $\begin{array}{l}\text { G8 } \\
\text { score }\end{array}$ & $\begin{array}{l}\text { Adverse } \\
\text { event }\end{array}$ & $\begin{array}{c}\text { Hematotoxicity, } \\
\text { neutropenia }\end{array}$ & $\begin{array}{c}\text { Survival time } \\
\text { (months), outcome }\end{array}$ & $\begin{array}{l}\text { Bladder preservation } \\
\text { (months) }\end{array}$ \\
\hline 1 & $84 / \mathrm{F}$ & II & 2 & 50 & $\mathrm{G} 2$ & 11 & Cystitis: G1 & G0 & 28 , Died from disease & 7 \\
\hline 2 & $86 / \mathrm{M}$ & III & 2 & 60 & $\mathrm{G} 2$ & 9 & Cystitis: G1 & G0 & 7, Died from disease & 3 \\
\hline 3 & $91 / M$ & II & 2 & 56 & $\mathrm{G} 2$ & 10 & Cystitis: G1 & $\begin{array}{l}\text { NHL after } \\
\text { treatment }\end{array}$ & 44, Survived & 44 \\
\hline 4 & 91/M & II & 2 & 50 & $\mathrm{G} 3>2$ & 10 & Cystitis: G1 & G1 & 10, Died from disease & 8 \\
\hline 5 & $84 / \mathrm{F}$ & III & 1.8 & 45 & $\mathrm{G} 2$ & 11 & None & G0 & 6, Died from disease & 3 \\
\hline 6 & $88 / \mathrm{M}$ & II & 2 & 50 & G3 & 10.5 & None & G1 & 13, Dropped out & 13 \\
\hline
\end{tabular}

*Urothelial cancer. G: Grade; NHL: non-Hodgkin's lymphoma. 


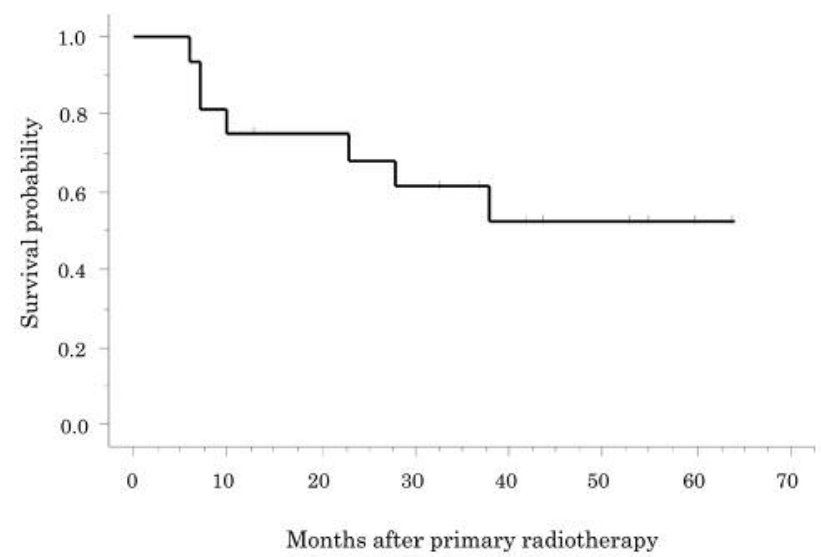

Figure 1. Overall survival curve of all patients.

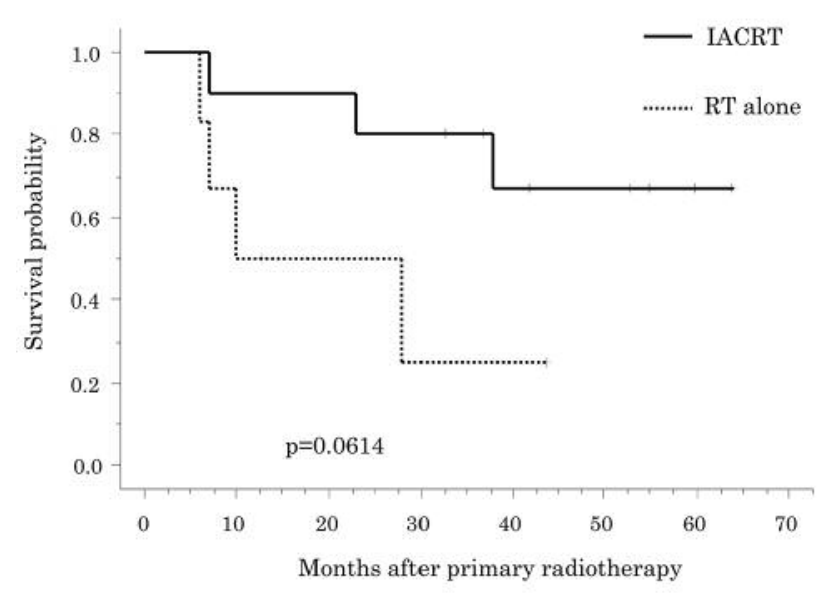

Figure 2. Overall survival in the radiotherapy $(R T)$ alone and intraarterial chemoradiotherapy (IACRT) groups. p-Values were calculated by the log-rank test stratified according to the treatment group.

Overall survival. Overall, the median follow-up period was 35 (range=6-64) months; it was 12 (range=6-44) months in the RT-alone group and 40 (range=6-64) months in the IACRT group. Overall, the 2-year and 5-year survival rates were $68.2 \%$ and $52.6 \%$, respectively (Figure 1), and the corresponding rates were $80 \%$ and $66.7 \%$ in the IACRT group. The 1-year and 2-year survival rates in the RT-alone group were $50 \%$ and $25 \%$, respectively (Figure 2).

Urinary bladder preservation and post-treatment. Overall, the bladder preservation rates at 2 and 5 years were $55.6 \%$ and $40.5 \%$, respectively (Figure 3 ), and the corresponding rates were $70 \%$ and $48 \%$ for the IACRT group. The bladder

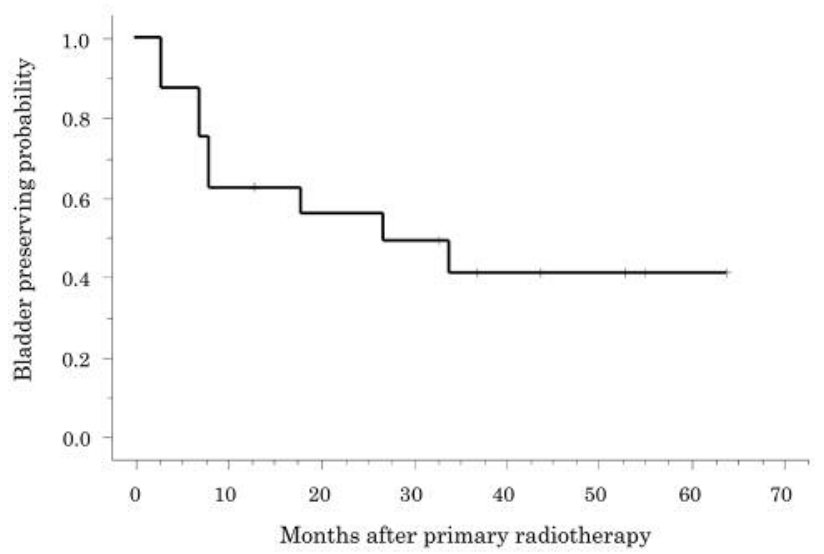

Figure 3. Bladder preservation curve considering all patients.

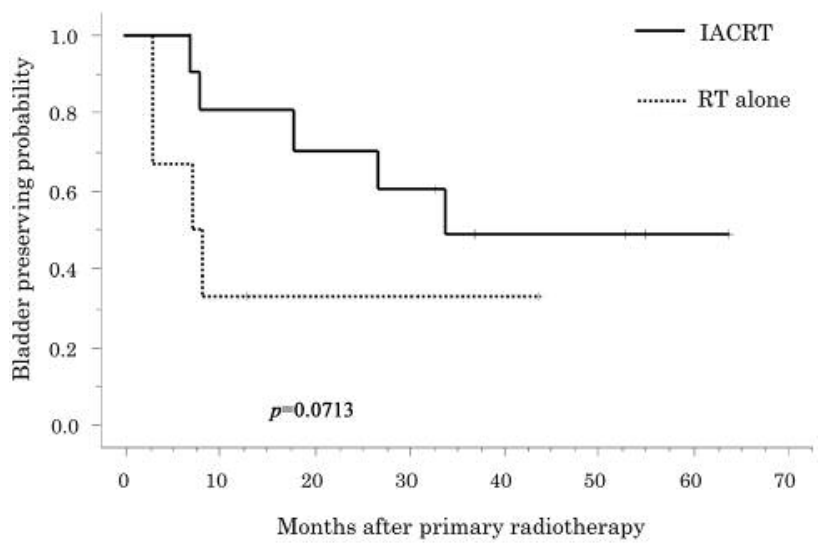

Figure 4. Bladder preservation in the radiotherapy $(R T)$ alone and intra-arterial chemoradiotherapy (IACRT) groups. p-Values were calculated by the log-rank test stratified according to the treatment group.

preservation rates at 1 and 3 years were both $33.3 \%$ in the RT-alone group (Figure 4). When patients experienced recurrence, doxifluridine or uracil-tegafur was used as posttreatment, or salvage treatment in combination with TURBT. Only one patient received gemcitabine alone.

Adverse events. Adverse events in the IACRT group included grade 3 or more severe hematotoxicity in five out of 10 cases and cystitis, as an acute-phase grade 2 adverse event, in one case (Tables II and III). Regarding late adverse events, there were no grade 2 or more severe urological or gastrointestinal adverse events. 


\section{Discussion}

Total cystectomy is the standard therapy for MIBC. However, postoperative recurrence rates of approximately $40 \%$ have been reported (1-3). Additionally, postoperative quality-of-life impairment resulting from urinary diversion after cystectomy cannot be ignored. Therefore, at present, RT is performed as radical or palliative therapy in patients who are poor candidates for surgery due to comorbidities. Moreover, elderly patients with MIBC are often frail and thus may reject surgery. In such cases, RT alone or CRT is usually selected. The combination of chemotherapy with RT has been reported to achieve good outcomes (14-21) and may be comparable to surgery in terms of treatment results (22).

At our hospital, the treatment policy when performing resection of MIBC in combination with RT is the use of IACRT, if feasible. Concurrent use of IAC is comprehensively determined at conferences attended by urologists and radiation oncologists. The reason for using IAC is that the dose of anticancer drugs can be reduced with local injection of highly concentrated anticancer drugs as compared with systemic chemotherapy. At our hospital, platinum agents are primarily used in chemotherapy regimens, although the guidelines have no clear standard as to whether the treatment should be monotherapy or a combination regimen (27). We perform combination chemotherapy according to our long-standing policy because we have not as yet compared platinum-based monotherapy with combination therapy. This remains a future challenge.

With regard to RT methods for MIBC, no definitive conclusion has been reached as to whether the area of irradiation should be the small pelvis or the entire urinary bladder. Moreover, there is no consensus on total radiation dose $(7,14)$. In reports from Japan, the total radiation dose is low when RT is combined with IAC (8-10).

At our institution, the total radiation dose is set lower than that in the guidelines (27) because even routine irradiation may cause unexpected complications in elderly patients (23-26). In addition, according to reports of adverse reactions in the treatment of prostate cancer (28) and uterine cervical cancer (29), hemorrhagic cystitis and atrophic cystitis associated with RT can occur as late adverse events, resulting in marked impairment of quality of life. In order to reduce adverse events, irradiation is delivered to the entire urinary bladder at our hospital, followed by boost irradiation when a large lesion is found after TURBT in patients concurrently receiving IAC.

The treatment results in latter-stage elderly patients at our hospital were comparable to those of a multicenter study by the Japanese Radiation Oncology Study Group (14), with tolerable adverse events. In the IACRT group, the 2- and 5-year survival rates were $80 \%$ and $66.7 \%$, and the bladder preservation rates were $70 \%$ and $48 \%$, respectively. These results suggest the importance of IACRT even in latter-stage elderly patients.
Furthermore, it is noteworthy that a small fraction of elderly patients do respond to concurrent invasive IAC.

The 2-year survival rate in the RT-alone group was $25 \%$, lower than that in a past report (14). Four out of our six patients $(66.7 \%)$ receiving RT alone died of their primary disease in less than 1 year. Although there might be some bias, these poor treatment results are considered to be associated with a large number of patients receiving palliative treatment. However, the difference between our two groups of latter-stage elderly patients did not reach statistical significance, showing only a trend $(p=0.06)$. The possible reasons for the combination of IAC plus RT being found not to have a significant impact on outcomes include the use of RT alone showing a certain efficacy (14) and the sample size having been small.

Considering that all latter-stage patients with MIBC had a PS of 1 during the study period, we examined whether the G8 Screening Tool $(12,28)$ might be applicable in determining concurrent use of IAC in elderly patients. The scores were 11 points or less in the RT-alone group and 12 points or more in the IACRT group. The results of this study showed a trend which reflects clinical judgment, suggesting that IAC may be concurrently used even in very elderly patients as long as the G8 score is at least 12 points. Cut-off scores for elderly patients of 14 points or more for the G8 Screening Tool have been recommended $(32,33)$. Our present results indicate that IACRT can reasonably be selected in patients with scores of at least 12 points, but such patients tended to experience more adverse events. Further study is needed to assess whether IAC may result in fewer adverse events than systemic chemotherapy.

The most important aspect of managing patients with MIBC is deciding the actual treatment policy in clinical practice, although the evaluation of the general PS may change over the limited time of conducting routine examinations. Since CRT is considered to be more beneficial than RT alone for MIBC (14-22), in the future, the G8 score may be used as a method of determining whether concurrent use of IAC would be beneficial. Meanwhile the population continues to age and, since treatment methods cannot be determined by age alone, we intend to further study MIBC as well as other diseases based on our present findings.

\section{Conclusion}

IAC was considered to be useful, with tolerable adverse events, for MIBC in elderly patients. Moreover, in addition to age and PS, the G8 Screening Tool may be used to determine the feasibility of performing IAC.

\section{Conflicts of Interest}

The Authors have no conflicts of interest to declare in regard to this study. 


\section{References}

1 Hautmann RE, de Petriconi RC, Pfeiffer C and Volkmer BG: Radical cystectomy for urothelial carcinoma of the bladder without neoadjuvant or adjuvant therapy: long-term results in 1100 patients. Eur Urol 61: 1039-1047, 2012.

2 Stein JP, Lieskovsky G, Cote R, Groshen S, Feng AC, Boyd S, Skinner E, Bochner B, Thangathurai D, Mikhail M, Raghavan D and Skinner DG: Radical cystectomy in the treatment of invasive bladder cancer: long-term results in 1,054 patients. J Clin Oncol 19: 666-675, 2001.

3 Ennis RD, Petrylak DP, Singh P, Bagiella E, O'Toole KM, Benson $\mathrm{MC}$ and Olsson CA: The effect of cystectomy, and perioperative methotrexate, vinblastine, doxorubicin and cisplatin chemotherapy on the risk and pattern of relapse in patients with muscle invasive bladder cancer. J Urol 163: 1413-1418, 2000.

4 Matsuda A, Matsuda T, Shibata A, Katanoda K, Sobue T, Nishimoto H; Japan Cancer Surveillance Research Group: Cancer incidence and incidence rates in Japan in 2007: a study of 21 population-based cancer registries for the Monitoring of Cancer Incidence in Japan (MCIJ) Project. Jpn J Clin Oncol 43: 328-336, 2013.

5 Coppin CM, Gospodarowicz MK, James K, Tannock IF, Zee B, Carson J, Pater J and Sullivan LD: mproved local control of invasive bladder cancer by concurrent cisplatin and preoperative or definitive radiation. The National Cancer Institute of Canada Clinical Trials Group. J Clin Oncol 14: 2901-2907, 1996.

6 James ND, Hussain SA, Hall E, Jenkins P, Tremlett J, Rawlings C, Crundwell M, Sizer B, Sreenivasan T, Hendron C, Lewis R, Waters R, Huddart RA, BC2001 Investigators: Radiotherapy with or without chemotherapy in muscle-invasive bladder cancer. N Engl J Med 366: 1477-1488, 2012.

7 Tunio MA, Hashmi A, Qayyum A, Mohsin R and Zaeem A: Whole-pelvis or bladder-only chemoradiation for lymph nodenegative invasive bladder cancer: single-institution experience. Int J Radiat Oncol Biol Phys 82: 457-462, 2012.

8 Miyanaga N, Akaza H, Shinohara N, Koyanagi T, Tsujino S, Miki M, Tobisu K, Niimi M and Hinotsu J: Assessment of QOL and survival for patients undergoing radical cystectomy or bladder preservation for invasive bladder cancer. Nihon Hinyokika Gakkai Zasshi 90: 445-453, 1999.

9 Mori K, Nomata K, Noguchi M, Eguchi J, Hayashi N and Kanetake H: Long-term follow up of patients with invasive bladder carcinoma receiving combined cisplatin-based intra-arterial chemotherapy and radiotherapy. Int J Urol 14: 591-594, 2007.

10 Mokarim A, Uetani M, Hayashi N, Sakamoto I, Minami K, Ogawa Y, Ochi M, Matsuoka Y, Hayashi K and Nomata K: Combined intraarterial chemotherapy and radiotherapy in the treatment of bladder carcinoma. Cancer 80: 1776-1785, 1997.

11 Cabinet Office, Government of Japan; http://www8.cao.go.jp/ kourei/whitepaper/w-2014/gaiyou/s1_1.html.

12 McCleary NJ, Wigler D, Berry D, Sato K, Abrams T, Chan J, Enzinger P, Ng K, Wolpin B, Schrag D, Fuchs CS, Hurria A and Meyerhardt: Feasibility of computer-based self-administered cancer-specific geriatric assessment in older patients with gastrointestinal malignancy. JA Oncologist 18: 64-72, 2013.

13 National Cancer Institute. Common terminology criteria for adverse events v4.0 (CTCAE). http://ctep.cancer.gov/protocol Development/electronic_applications/docs/ctcae_4_with_lay_ter ms.pdf (accessed 12 April 2016).
14 Maebayashi T, Ishikawa H, Yorozu A, Yoshida D, Katoh H, Nemoto K, Ishihara S, Takemoto S, Ishibashi N, Tokumaru S, Akimoto T; Working Subgroup of Urological Cancers in Japanese Radiation Oncology Study Group: Patterns of practice in the radiation therapy for bladder cancer: survey of the Japanese Radiation Oncology Study Group (JROSG). Jpn J Clin Oncol 44: 1109-1115, 2014.

15 Tester W, Porter A, Asbell S, Coughlin C, Heaney J, Krall J, Martz K, Venner P and Hammond E: Combined modality program with possible organ preservation for invasive bladder carcinoma: results of RTOG protocol 85-12. Int J Radiat Oncol Biol Phys 25: 783-790, 1993.

16 Efstathiou JA, Spiegel DY, Shipley WU, Heney NM, Kaufman DS, Niemierko A, Coen JJ, Skowronski RY, Paly JJ, McGovern FJ and Zietman AL: Long-term outcomes of selective bladder preservation by combined-modality therapy for invasive bladder cancer: the MGH experience. Eur Urol 61: 705-711, 2012.

17 Kaufman DS, Winter KA, Shipley WU, Heney NM, Wallace HJ 3rd, Toonkel LM, Zietman AL, Tanguay S and Sandler HM: Phase I-II RTOG study (99-06) of patients with muscle-invasive bladder cancer undergoing transurethral surgery, paclitaxel, cisplatin, and twice-daily radiotherapy followed by selective bladder preservation or radical cystectomy and adjuvant chemotherapy. Urology 73: 833-837, 2008.

18 Higano CS, Tangen CM, Sakr WA, Faulkner J, Rivkin SE, Meyers FJ, Hussain M, Baker LH, Russell KJ, Crawford ED; Southwest Oncology Group Trial 8733: Treatment options for muscleinvasive urothelial cancer for patients who were not eligible for cystectomy or neoadjuvant chemotherapy with methotrexate, vinblastine, doxorubicin, and cisplatin: report of Southwest Oncology Group Trial 8733. Cancer 112: 2181-2187, 2008.

19 Tester W, Caplan R, Heaney J, Venner P, Whittington R, Byhardt R, True L and Shipley W: Neoadjuvant combined modality program with selective organ preservation for invasive bladder cancer: results of Radiation Therapy Oncology Group phase II trial 8802. J ClinOncol 14: 119-126, 1996.

20 James ND, Hussain SA, Hall E, Jenkins P, Tremlett J, Rawlings C, Crundwell M, Sizer B, Sreenivasan T, Hendron C, Lewis R, Waters R, Huddart RA; BC2001 Investigators: Radiotherapy with or without chemotherapy in muscle-invasive bladder cancer. N Engl J Med 366: 1477-1488, 2012.

21 Zapatero A, Martin De Vidales C, Arellano R, Ibañez Y, Bocardo G, Perez M, Rabadan M, García Vicente F, Cruz Conde JA and Olivier C: Long-term results of two prospective bladder-sparing trimodality approaches for invasive bladder cancer: neoadjuvant chemotherapy and concurrent radiochemotherapy. Urology 80 : 1056-1062, 2012.

22 Yoshioka H, Shimbo T, Yoshida K, Yoshikawa N, Uesugi Y, Yamamoto K, Azuma $\mathrm{H}$ and Narumi Y: Treatment results of radiotherapy combined with balloon-occluded arterial infusion chemotherapy for invasive bladder cancer. Anticancer Res 36 : 731-736, 2016.

23 Jalal SI, Riggs HD, Melnyk A, Richards D, Agarwala A, Neubauer M, Ansari R, Govindan R, Bruetman D, Fisher W, Breen T, Johnson CS, Yu M, Einhorn L and Hanna N: Updated survival and outcomes for older adults with inoperable stage III non-small-cell lung cancer treated with cisplatin, etoposide, and concurrent chest radiation with or without consolidation docetaxel: analysis of a phase III trial from the Hoosier Oncology Group (HOG) and US Oncology. Ann Oncol 23: 1730-1738, 2012. 
24 Kasenda B, Ferreri AJ, Marturano E, Forst D, Bromberg J, Ghesquieres H, Ferlay C, Blay JY, Hoang-Xuan K, Pulczynski EJ, Fosså A, Okoshi Y, Chiba S, Fritsch K, Omuro A, O’Neill BP, Bairey O, Schandelmaier S, Gloy V, Bhatnagar N, Haug S, Rahner $\mathrm{S}$, Batchelor TT, Illerhaus G and Briel M: First-line treatment and outcome of elderly patients with primary central nervous system lymphoma (PCNSL)-a systematic review and individual patient data meta-analysis. Ann Oncol 26: 1305-1313, 2015.

25 Harada H, Seto T, Igawa S, Tsuya A, Wada M, Kaira K, Naito $\mathrm{T}$, Hayakawa $\mathrm{K}$, Nishimura $\mathrm{T}$, Masuda $\mathrm{N}$ and Yamamoto $\mathrm{N}$ : Phase I results of vinorelbine with concurrent radiotherapy in elderly patients with unresectable, locally advanced non-smallcell lung cancer: West Japan Thoracic Oncology Group (WJTOG3005-DI). Int J Radiat Oncol Biol Phys 82: 1777-1782, 2012.

26 O’Neill CB, Baxi SS, Atoria CL, O’Neill JP, Henman MC, Sherman EJ, Lee NY, Pfister DG and Elkin EB: Treatmentrelated toxicities in older adults with head and neck cancer: A population-based analysis. Cancer 121: 2083-2089, 2015.

27 NCCN Guidelines Version 2.2014 (NCCN: National Comprehensive Cancer Network $\left.{ }^{\circledR}\right)$ https://www.nccn. org /professionals/physician_gls/pdf/bladder.pdf (accessed 12 April 2016).

28 Heemsbergen WD, Al-Mamgani A, Witte MG, van Herk M, Pos FJ and Lebesque JV: Urinary obstruction in prostate cancer patients from the Dutch trial (68 Gy vs. 78 Gy): relationships with local dose, acute effects, and baseline characteristics. Int J Radiat Oncol Biol Phys 78: 19-25, 2010.

29 Uezono H, Tsujino K, Moriki K, Nagano F, Ota Y, Sasaki R and Soejima T: Pelvic insufficiency fracture after definitive radiotherapy for uterine cervical cancer: retrospective analysis of risk factors. J Radiat Res 54: 1102-1109, 2013.
30 Luciani A, Biganzoli L, Colloca G, Falci C, Castagneto B, Floriani I, Battisti N, Dottorini L, Ferrari D, Fiduccia P, Zafarana E, Del Monte F, Galli F, Monfardini S and Foa P: Estimating the risk of chemotherapy toxicity in older patients with cancer: The role of the Vulnerable Elders Survey-13 (VES-13). J Geriatr Oncol 6: 272-279, 2015.

31 Kenis C, Decoster L, Van Puyvelde K, De Grève J, Conings G, Milisen K, Flamaing J, Lobelle JP and Wildiers H: Performance of two geriatric screening tools in older patients with cancer. $\mathrm{J}$ Clin Oncol 32: 19-26, 2014.

32 Velghe A, Petrovic M, De Buyser S, Demuynck R and Noens L: Validation of the G8 screening tool in older patients with aggressive haematological malignancies. Eur J Oncol Nurs 18: 645-648, 2014

33 Bellera CA, Rainfray M, Mathoulin-Pélissier S, Mertens C, Delva F, Fonck $M$ and Soubeyran PL: Screening older cancer patients: first evaluation of the G-8 geriatric screening tool. Ann Oncol 2166-2172, 2012.
Received June 23, 2016

Revised July 9, 2016

Accepted July 11, 2016 